\title{
Initial fate of fine ash and sulfur from large volcanic eruptions
}

\author{
U. Niemeier ${ }^{1}$, C. Timmreck ${ }^{1}$, H.-F. Graf ${ }^{2}$, S. Kinne ${ }^{1}$, S. Rast ${ }^{1}$, and S. Self ${ }^{3}$ \\ ${ }^{1}$ Max Planck Institute for Meteorology, Bundesstr. 53, 20146 Hamburg, Germany \\ ${ }^{2}$ University of Cambridge, Centre for Atmospheric Science, Downing Place, Cambridge, CB2 3EN, UK \\ ${ }^{3}$ Department of Earth Science, Open University, Milton Keynes, MK7 6AA, UK
}

Received: 8 June 2009 - Published in Atmos. Chem. Phys. Discuss.: 24 August 2009

Revised: 17 November 2009 - Accepted: 23 November 2009 - Published: 30 November 2009

\begin{abstract}
Large volcanic eruptions emit huge amounts of sulfur and fine ash into the stratosphere. These products cause an impact on radiative processes, temperature and wind patterns. In simulations with a General Circulation Model including detailed aerosol microphysics, the relation between the impact of sulfur and fine ash is determined for different eruption strengths and locations, one in the tropics and one in high Northern latitudes. Fine ash with effective radii between $1 \mu \mathrm{m}$ and $15 \mu \mathrm{m}$ has a lifetime of several days only. Nevertheless, the strong absorption of shortwave and long-wave radiation causes additional heating and cooling of $\pm 20 \mathrm{~K} /$ day and impacts the evolution of the volcanic cloud. Depending on the location of the volcanic eruption, transport direction changes due to the presence of fine ash, vortices develop and temperature anomalies at ground increase. The results show substantial impact on the local scale but only minor impact on the evolution of sulfate in the stratosphere in the month after the simulated eruptions.
\end{abstract}

\section{Introduction}

Volcanic aerosols are an active component of the climate system and play multiple roles in physical and biogeochemical exchanges between the atmosphere, land surface and ocean. The impact of sulfuric aerosols on climate after a volcanic eruption has been comprehensively studied, but in General Circulation models (GCMs) mainly aerosol bulk models assuming a fixed aerosol partition (Oman et al., 2006; Timmreck et al., 1999, 2003) or a prescribed aerosol distribution e.g. (Stenchikov et al., 1998; Kirchner et al., 1999; Thomas et al., 2009) was used so far. The simulations presented here are different to previous GCM studies because they include

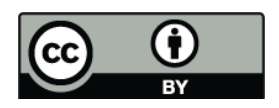

Correspondence to: $\mathrm{U}$. Niemeier (ulrike.niemeier@zmaw.de) detailed aerosol microphysics, calculating the nucleation and accumulation processes as well as the aerosol size distribution in detail.

The impact of volcanic eruptive products on climate strongly depends on eruption strength and height of the resulting plume. An eruption has a long (month to years) climatic influence when the ash and $\mathrm{SO}_{2}$ cloud reaches the stratosphere. In the troposphere the eruption products are quickly sedimented and washed out. Only in the stratosphere they can be dispersed over long distances. Additionally, the influence of the volcanic eruption depends on the location. Volcanos in the tropics have a global effect and high latitude volcanos show a more regional to hemispheric effect.

Little attention has been paid to the impact of fine ash on climate and biogeochemical processes. Volcanic ash is composed of silicate (including glass and sometimes mineral components) that scatters and absorbs infrared light differently from water and ice in the atmosphere. Fine ash can be globally transported and change chemistry, cloudiness and radiation budget of the atmosphere for a few weeks. The 15 June 1991 climactic eruption of Mt. Pinatubo for example, covered an area of approximately $4 \times 10^{5} \mathrm{~km}^{2}$ with a minimum of $1 \mathrm{~mm}$ ash on Luzon Island and across the South China Sea (Wiesner et al., 2004).

Over the ash-covered areas the surface albedo and hydrology are changed significantly with consequences on local and potentially global climate (Jones et al., 2007). Agriculture and biosphere are heavily affected by ash deposits. A layer of volcanic ash one centimetre thick disrupt most forms of agriculture for more than a growing season, and lesser amounts (a few millimetres) can destroy many kinds of crops (e.g. Self (2006)). Furthermore, changes in soil composition can be expected. Deposition of volcanic ash may provide an external nutrient source for primary production in ocean surface waters, in particular through iron fertilisation (Duggen et al., 2007). This effect is strongest in high-nutrient but lowproductivity (low-iron) areas in the Pacific and the Southern

Published by Copernicus Publications on behalf of the European Geosciences Union. 
Ocean. Surrounded by active volcanoes, in these areas the fallout of ash can have a high potential to induce globally significant, transient net $\mathrm{CO}_{2}$ removal from the upper ocean and hence from the atmosphere.

During the past years, it has been possible to detect fine ash by satellite instruments (e.g. Prata and Kerkmann, 2007; Guo et al., 2004). This is extremely helpful for aviation safety, as fine ash is a source of danger, which in low concentration can not be seen by the pilots of an air plane (Tupper et al., 2004). The transport of ash has been simulated in dispersion models (e.g. PUFF) with prescribed meteorological fields (Searcy et al., 1998; Fero et al., 2008). Folch et al. (2008) coupled an ash dispersion model to the Weather research and Forecasting model (WRF), allowing also to forecast the dispersion of ash. These studies were not concerned with the interaction of the ash cloud to radiative processes, thus neglecting the interaction between cloud and meteorological processes. On the other hand, the Active Tracer High Resolution Atmospheric Model ATHAM (Textor et al., 2006; Herzog et al., 1998) and the 3-D simulation by Suzuki and Koyaguchi (2009) show detailed information on the processes in the eruption cloud on the local scale in the very first phase, i.e. few hours, of the eruption.

This paper determines the impact of fine ash, emitted into the stratosphere by large volcanic eruptions $\left(5 \mathrm{~km}^{3}\right.$ erupted material and above), on meteorological processes and tracer transport on the global scale for several days. Even though ash has a short atmospheric lifetime, the indirect effect of changing wind patterns caused by the radiative impact of ash, influences other tracers like sulfate with potentially global effects. To calculate these indirect impacts, radiative parameters of ash are taken into account, the size of the ash particles changes with time and sedimentation and deposition are included as sink processes. For these studies the global general circulation model MAECHAM5 was used including the interactively coupled aerosol microphysics model HAM. By comparison with observations, we show the capability of MAECHAM5-HAM to simulate the evolution of a volcanic cloud consisting of ash and sulfate shortly after the eruption as well as in a longterm perspective (Sect. 4). Thereafter the impact of ash on meteorological processes is investigated for two volcanic eruption locations, one in the tropics and one at high latitudes (Sect. 5). The eruption locations were chosen to provide different radiative conditions and background flow patterns, an impact on both the transport and dispersion of the volcanic cloud. To further distinguish the role of heating processes we vary season and strength of the eruption. The discussion of results will focus on the impact of fine ash during the first four weeks after the eruption. We will emphasise the direct impact on heating rates and temperatures and determine longer lasting indirect impact on the lifetime of sulfate is possible, depending on location and emission strength.

\section{Model description}

The study was performed with the general circulation model MAECHAM5 (Giorgetta et al., 2006), a middle atmosphere version of the ECHAM5 model (Roeckner et al., 2003). The model solves prognostic equations for vorticity, divergence, surface pressure and temperature, expressed in terms of spherical harmonics with a triangular truncation. Water vapour, cloud liquid water, cloud ice and trace components are transported with a flux form semi-Lagrangian transport scheme (Lin and Rood, 1996). MAECHAM5 is integrated with a spectral truncation of 42 (T42) and 39 vertical levels up to $0.01 \mathrm{hPa}$. The integration is performed with a time step of $900 \mathrm{~s}$.

\subsection{Fine ash}

For this study, a fine ash module was included into MAECHAM5. To calculate the transport and distribution of fine ash, two passive tracers were introduced into the model: ash mass and number concentration. They are transported independently from each other, thus the mean radius of fine ash varies over time.

Sedimentation, wet and dry deposition processes are implemented similar to the processes for dust in the ECHAM5 aerosol microphysics module HAM (Stier et al., 2005). The emitted fine ash is assumed to be non-soluble particulates with a mean radius of $2.4 \mu \mathrm{m}$, an effective radius of $5.7 \mu \mathrm{m}$, and a density of a single fine ash particle of $2400 \mathrm{~kg} / \mathrm{m}^{3}$. For the log-normal distribution of particle size, a fixed standard deviation $\sigma=1.8$ is assumed.

Optical parameters for fine ash are calculated from the time dependent aerosol mass mixing ratio, normalised extinction and absorption coefficients, and a normalised asymmetry factor. To derive these normalised parameters, dependent on wavelength and size, Mie calculations were performed for all spectral bands of the MAECHAM5 radiation scheme. Therefore, refractive indices for rhyolite were used (Pollack et al., 1973) and the results stored in a look-up table. The look-up table covers effective radii of particles between $0.5 \mu \mathrm{m}-10 \mu \mathrm{m}$.

\subsection{Sulfur}

The formation of sulfate aerosol is calculated by the aerosol module HAM (Stier et al., 2005), which is interactively coupled to ECHAM5. The mode setup of M7, the microphysical core of HAM, (Vignati et al., 2004) was changed according to boxmodel studies for large volcanic eruptions (Kokkola et al., 2009). The changes include a new time integration scheme of $\mathrm{H}_{2} \mathrm{SO}_{4}$ processes, a revised nucleation parameterisation (Vehkamäki, personal communication, 2008), a reduction to three modes (nucleation, aitken, accumulation), and a smaller standard deviation for the accumulation mode ( $\sigma=1.2$ instead of $\sigma=1.59$ ). The simulation includes only 
Table 1. Simulations performed for the two different volcanic eruption sites. Pt1_ens, Kat1_ens, Pt10_ens and Kat10_ens contain each an ensemble of five simulations. For both sites total emissions comparable to the Mt. Pinatubo eruptions are assumed: $1 \times$ : emissions of $17 \mathrm{Mt} \mathrm{SO}_{2}$ and $100 \mathrm{Mt}$ fine ash in $3 \mathrm{~h} ; 10 \times$ : emissions of $1700 \mathrm{Mt}$ $\mathrm{SO}_{2}$ and $10000 \mathrm{Mt}$ fine ash in $30 \mathrm{~h}$.

\begin{tabular}{llll}
\hline Eruption date & \multicolumn{2}{c}{1 June } & 1 January \\
\hline Eruption strength & $1 \times$ & $10 \times$ & $1 \times$ \\
Pinatubo & Pt1_ens & Pt10_ens & Pt1w_ens \\
Katmai & Kat1_ens & Kat10_ens & Kat1w \\
\hline
\end{tabular}

sulfate aerosol, other aerosols normally used in HAM (e.g. black carbon, organic carbon, sea salt, dust) were ignored. Sulfur chemistry is calculated in the troposphere as described in Feichter et al. (1996), and in the stratosphere as in Hommel (2008) and Steil et al. (2003). Climatological concentrations of background $\mathrm{OH}$ values have been taken from Timmreck et al. (2003), other gas-phase species from Jöckel et al. (2005).

\section{Simulations}

The sensitivity study investigates the impact of ash on transport and dispersion of the volcanic cloud and distinguishes the role of location of the volcano, eruption strength and season of eruption. MAECHAM5 was used in the climate mode. This free running setup has no quasi-biennialoscillation (QBO) and we have not forced the model to "real meteorological conditions" via nudging as this might also suppress the impact of the volcanic emissions on the flow pattern. The volcanic eruption took place after 17 months of initial simulation. We performed an ensemble of five simulations by imposing a small disturbance on the absorption layer at the model top shortly before the eruption. With this setup we simulated the aerosol micro-physical evolution of the volcanic cloud for two different volcanic eruption sites (Table 1): Mt. Pinatubo $\left(15.14^{\circ} \mathrm{N}, 120.35^{\circ} \mathrm{E}\right)$ in the tropics and Mt. Katmai, Alaska $\left(58.2^{\circ} \mathrm{N}, 155^{\circ} \mathrm{W}\right)$ in the northern hemispheric higher latitudes. At each location one simulation always contained $\mathrm{SO}_{2}$ and fine ash emissions and one $\mathrm{SO}_{2}$ emissions only. Total volcanic emissions of $17 \mathrm{Mt} \mathrm{SO}_{2}$ and 100 Mt fine ash, as from Mt. Pinatubo in June 1991 (Read et al., 1993; Krueger et al., 1995), were assumed. To test the influence of eruption strength, a 10 times larger eruption was performed as well. The eruption always started at $1 \mathrm{st}$ of June at 06:00 UTC and lasted for $3 \mathrm{~h}$ and for $30 \mathrm{~h}$ in case with 10 times higher emissions. Thus emissions rate was for both $1.5 \times 10^{6} \mathrm{~kg}\left(\mathrm{SO}_{2}\right) / \mathrm{s}$ and for fine ash $2.77 \times 10^{7} \mathrm{~kg} / \mathrm{s}$. To get a more general view on the impact of the fine ash, under varying meteorological conditions, additional simulations for winter eruptions were performed. As our focus is on the impact of the fine ash in eruptions at different latitudes, we have chosen the same volcanic strength for both locations to maintain a better comparability. Mt. Katmai can be seen as synonym for any volcano in Southern Alaska. The eruption strength is not related to the real eruption in 1912, when no reliable measurements were available.

$\mathrm{SO}_{2}$ is injected into the stratosphere into a model layer corresponding to the pressure height level of $30 \mathrm{hPa}(\sim 24 \mathrm{~km})$. Satellite observations and ATHAM simulations show that the neutral buoyancy height of ash is lower than that of $\mathrm{SO}_{2}$ (Schneider et al., 1999; Holasek et al., 1996b). Therefore, fine ash was released at a height of $50 \mathrm{hPa} . \mathrm{SO}_{2}$ and fine ash each are emitted into one grid box at the latitude and longitude of the volcano. For the initial amount of fine ash emitted into the stratosphere we use an amount commensurate with that emitted by Pinatubo and satellite retrieval data (Guo et al., 2004). We inject a total fine ash particle number of $7.93 \times 10^{22}$ and a total fine ash mass of $100 \mathrm{Mt}$ over three hours into the stratosphere $(50 \mathrm{hPa}, \sim 21 \mathrm{~km})$. This corresponds to ca. $1 \%$ of the total erupted mass. $66 \mathrm{Mt}$ of the totally emitted fine ash are in the 1 to $15 \mu \mathrm{m}$ size range of ash particles, comparable to the amount detected by satellite measurements, which suggested 0.6 to $0.9 \%$ (Guo et al., 2004 ) and 0.7 to $0.9 \%$ (Wen and Rose, 1994) of the total erupted mass injected into the stratosphere.

\section{Comparison to measurements}

The eruption of Mt. Pinatubo was the largest one in the last decades ( $\sim 5 \mathrm{~km}^{3}$ of magma emitted). The processes following in the atmosphere were well documented by observations and therefore taken as a test case. We compare our simulation results of detailed aerosol formation and evolution processes to measurements of satellite and lidar instruments. Showing the impact of fine ash on the evolution of the volcanic cloud, we have to compare the results of the aerosol micro-physics and transport processes to measurements in a short term as well as in a longterm perspective. Results in this section are based on a single simulation in the climate mode.

\subsection{Fine ash}

An effective radius ( $r_{\text {eff }}$ ) of fine ash between 6.2 and $9.33 \mu \mathrm{m}$ has been retrieved from satellite measurements (Guo et al., 2004) for the first 5 days after the Mt. Pinatubo eruption. ECHAM5-HAM calculates effective radii of $6 \mu \mathrm{m}$, quickly decreasing over time to $3 \mu \mathrm{m}$. These values are at the lower limit of the satellite retrieval. Figure 1 (left) shows results from the satellite retrieval of HIRS/2 analysed by Guo et al. (2004) after the Mt. Pinatubo eruption and the fine ash mass as calculated in MAECHAM5 for the first days after the eruption. The model gives higher values in the beginning with a quicker decrease of the total fine ash mass and a slower decline after the larger particles are sedimented. After three days $r_{\text {eff }}$ is smaller in the model than in the satellite retrievals 

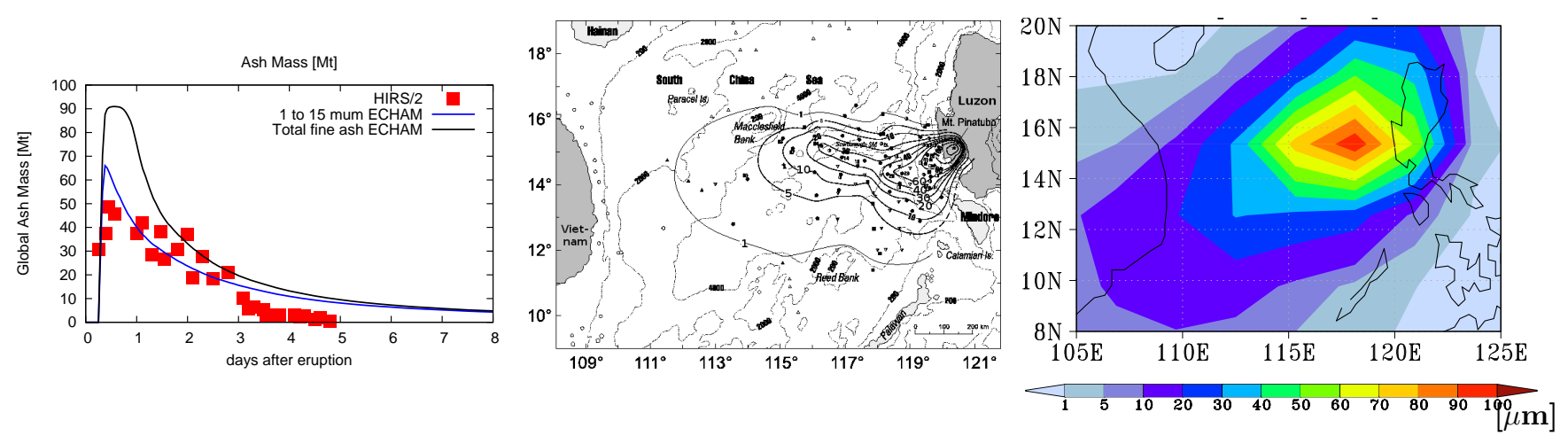

Fig. 1. Left: Evolution of the global mass of fine ash in the first days after the Mt. Pinatubo eruption. The red squares show results of satellite measurements in the size range of $1 \mu \mathrm{m}$ to $15 \mu \mathrm{m}$ (Guo et al., 2004), the curves give model results of the total fine ash amount (black) and the amount of fine ash in the $1 \mu \mathrm{m}$ to $15 \mu \mathrm{m}$ size interval.

Right: Measured fine ash fall out [mm] after Wiesner et al. (2004) (middle) and simulated fine ash fall out [ $\mu \mathrm{m}]$ in the first month after the Mt. Pinatubo eruption.

(Guo et al., 2004) and sedimentation velocity slows down. The ash cloud is dispersed by this time and parts of the cloud with low concentrations might be below the detection limit of the satellite. These areas with lower concentrations are, however, included in the global sum of the simulation results. Hence, we conclude that the simulated fine ash properties agree reasonably well with the observations.

A comparison of the simulated deposition of Mt. Pinatubo fine ash (Fig. 1, right) with sediment trap measurements of Wiesner et al. (2004) shows a very similar pattern, even though the passing of Typhoon Yunya ${ }^{1}$ was not included in the simulation. This similarity suggests that also larger particles, as found in the sediment traps, reach the stratosphere and are transported with the main stratospheric flow, independent of the Typhoon. The larger particles are not included in the simulation, thus the thickness of the simulated fine ash layer is much smaller as observed.

\subsection{Sulfate}

For a realistic simulation of the volcanic sulfate cloud in the stratosphere, the evolution process of the sulfate and the calculated size of the aerosol is important. To obtain confidence in the simulated evolution of sulfate and on the impact of ash, we compare the model results over a period of two years to observations. For sulfur, being emitted as $\mathrm{SO}_{2}$, the assumed climatological $\mathrm{OH}$ concentration determines the oxidation rate of $\mathrm{SO}_{2}$ to $\mathrm{H}_{2} \mathrm{SO}_{4}$ and the lifetime of $\mathrm{SO}_{2}$. Sulfate particles are formed by gas to particle transition from $\mathrm{H}_{2} \mathrm{SO}_{4}$ by condensation, nucleation and coagulation.

Figure 2 shows the rapid decrease of the total global mass of $\mathrm{SO}_{2}$ after the eruption. The yellow line represents the sim-

\footnotetext{
${ }^{1}$ Yunya passed about $75 \mathrm{~km}$ northeast of Mt. Pinatubo during the initial stage of the climactic eruption (further details in Wiesner et al. (2004)).
}

ulation results, in green and red, results of TOMS and TOVS satellite data are given (Guo et al., 2004). The measured $\mathrm{SO}_{2}$ concentration decreases with an e-folding time of $23 \pm 5$ days (TOMS) and $25 \pm 5$ days (TOVS). The simulated e-folding time of 33 days agrees however well to MLS satellite measurements (33 days) (Read et al., 1993) and previous TOMS data retrievals (35 days) of Bluth et al. (1992). The model does not include a full stratospheric chemistry. Therefore, possible influences of the volcanic eruption on $\mathrm{OH}$ and $\mathrm{O}_{3}$ concentrations were not considered.

Figure 2 (top) shows a slight overestimation of the simulated global $\mathrm{SO}_{4}^{2-}$ concentration maximum compared to HIRS measurements between $80^{\circ} \mathrm{N}$ and $80^{\circ} \mathrm{S}$ (Baran and Foot, 1994). The simulated concentration declines 200 days after the eruption when the measurements still remain on a higher level. One year after the eruption the simulated concentration is lower than the observed one. The onset of the declining concentration in the simulation coincides with the period of simulated maximum effective radius $\left(\mathrm{r}_{\mathrm{eff}}\right)$ of the sulfate particle size distribution in the accumulation mode of $0.5 \mu \mathrm{m}$ (Fig. 2, bottom). The effective radius increases earlier and the values are in the upper range of the measurements. This effect is even stronger at height levels between 12 and $16 \mathrm{~km}$, indicating a faster accumulation of particles and stronger sedimentation. The decline of the simulated $\mathrm{SO}_{4}^{2-}$ concentration slows down about 500 days after the eruption, when $\mathrm{r}_{\text {eff }}$ becomes smaller than $0.4 \mu \mathrm{m}$.

In Fig. 3, model results of the column mass are compared to lidar measurements taken in the northern mid latitude (Jäger et al., 1995). Measurements and model values increase with a similar slope. The maximum model concentration is reached one to two months earlier than in the measurements, indicating faster northward transport, and the period with maximum concentrations is shorter. Until about 450 days after the eruption, measurements and model data agree 

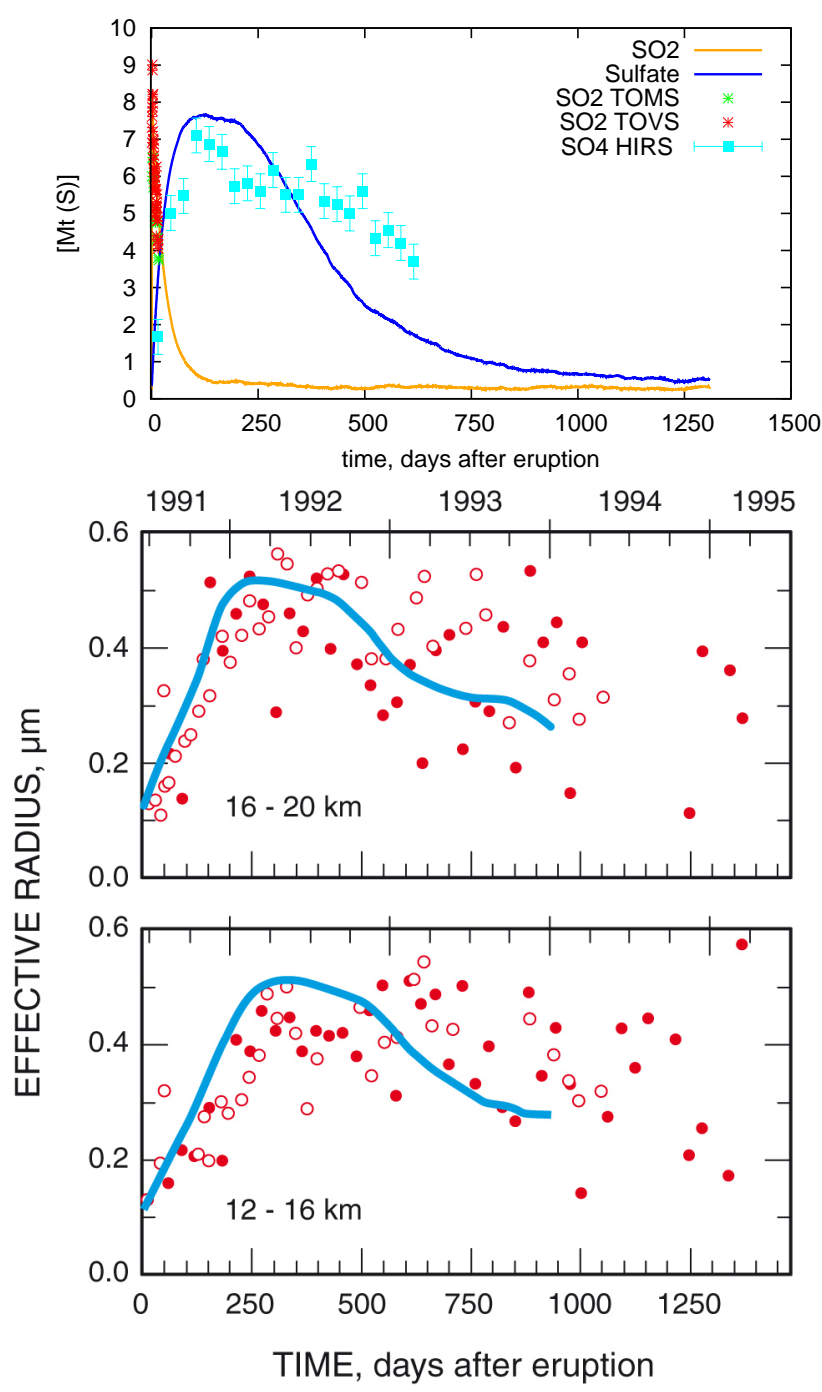

Fig. 2. Top: Global mass of $\mathrm{SO}_{2}$ and sulfate in the MAECHAM5HAM simulations (lines) and satellite measurements (HIRS) (Baran and Foot, 1994), TOMS and TOVS (Guo et al., 2004) after the Mt. Pinatubo eruption.

Bottom: Effective radius at Northern Hemisphere mid latitudes after the Mt. Pinatubo eruption at two different heights. The circles represent lidar measurements at Laramie $41^{\circ} \mathrm{N}$ (open circle) and Geesthacht $53.4^{\circ} \mathrm{N}$ (closed circle) (Ansmann et al., 1997) and the blue line zonal mean model results at $53^{\circ} \mathrm{N}$.

well. Thereafter the simulations show declining values while the measurements indicate increasing values again. This increase of the concentrations in the measurements showed in Fig. 3 is related to seasonal variations of the tropopause height (Timmreck et al., 1999) and must be regarded as an artefact of the analysis method.

The patterns of simulated Aerosol Optical Depth (AOD) (Fig. 4, top) are very similar to AVHRR and SAGE satellite measurements (Fig. 4, bottom). Both show maximum values along the equator and secondary maxima at $60^{\circ} \mathrm{N}$. The model results also show a secondary maximum around $60^{\circ} \mathrm{S}$ with transport towards the pole after the southern polar vortex breaks down. In this area the satellite measurements also include a signal of the aerosols emitted by the August 1991 eruption of Cerro Hudson (45.9 $\left.\mathrm{S}, 79.96^{\circ} \mathrm{W}\right)$, which is not included in the model simulation. It is noteworthy that the similar pattern in measurements and model results suggest a dominance of Pinatubo aerosol in the southern hemisphere and not of aerosols originating from Cerro Hudson. In the model results the tropical maximum is not persistent and the location of the maximum is half a year after the eruption north and not south of the equator, as in the measurements. According to Trepte and Hitchman (1992) in the stratosphere exists an upper and a lower transport regime: below $50 \mathrm{hPa}$ fast meridional poleward transport dominates, above $30 \mathrm{hPa}$ one finds longer tropical residence times. Even though the aerosols stay above $50 \mathrm{hPa}$, the poleward transport in the model is overestimated. This is a model artefact and has also been shown in other model studies (Timmreck et al., 1999; Oman et al., 2006).

The simulated AOD is probably overestimated by 10 to $20 \%$. Due to overestimated Sun photo-meter measurements, AVHRR measurements in 1991 should be corrected by a factor of 0.84 (Russell et al., 1996). The AVHRR measurements show a maximum of 0.39 (uncorrected 0.47 ) and the simulated AOD maximum is 0.44 . From the SAGE measurements even smaller values are reported, which were caused by an initial super-saturation of the instrument (Russell et al., 1996). One year after the eruption, SAGE data are more reliable and agree quite well with the simulated values. Our simulated spatio-temporal distribution of AOD agrees well with the observations, even though atmospheric dynamics were not forced to represent the actual dynamics of the years 1991-1993.

A comparison of the transport of ash and $\mathrm{SO}_{2}$ clouds with satellite measurements (Guo et al., 2004) in the first days after the eruption shows a good representation of the transport in ECHAM5. Due to different injection heights, the ash cloud is advected slower to the west than the $\mathrm{SO}_{2}$ cloud, similar to the observations. The simulated $\mathrm{SO}_{2}$ cloud is advected slightly faster than observed. A second simulation with another eruption day and different wind conditions in the stratosphere (Pt1-5), agrees even better with the observations.

The grid resolution of the model is not sufficient to simulate the rotation of the umbrella cloud in the initial few hours, described in Holasek et al. (1996a) and Chakraborty et al. (2009). Baines et al. (2008) suggest a strong impact of this short-lasting initial rotation on the transport of the particles in the following days. We can conclude from the good representation of transport in our results that this rotation does not necessarily have a strong impact on the advection of the Mt. Pinatubo cloud after the initial eruption phase. 

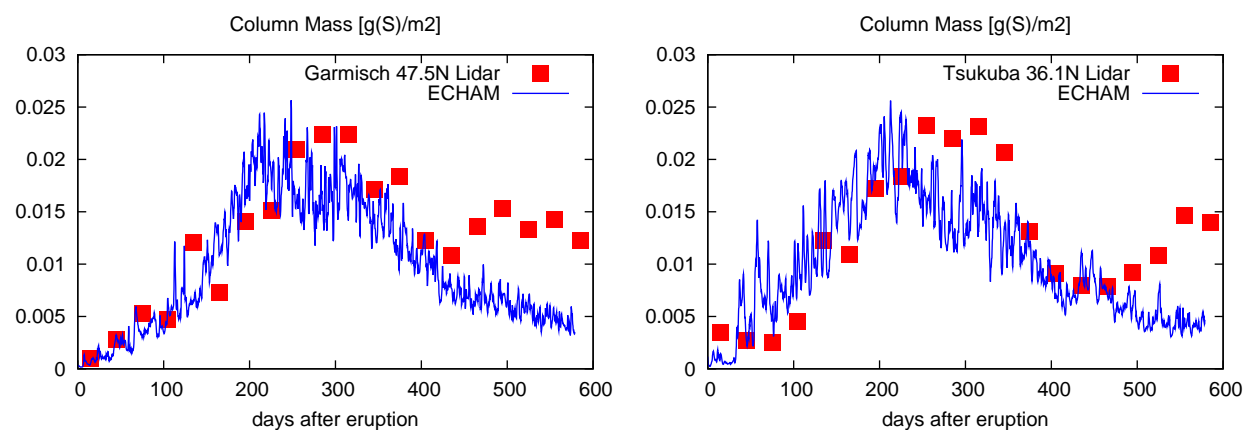

Fig. 3. Monthly mean column mass of sulfate $\left[\mathrm{g}(\mathrm{S}) / \mathrm{m}^{2}\right]$ after the Mt. Pinatubo eruption. Lidar measurements at Garmisch $\left(47.5^{\circ} \mathrm{N}\right)$ and Tsukuba $\left(36.1^{\circ} \mathrm{N}\right)$ (Jäger et al., 1995) are indicated as red squares and simulated values for the corresponding model grid as blue lines.
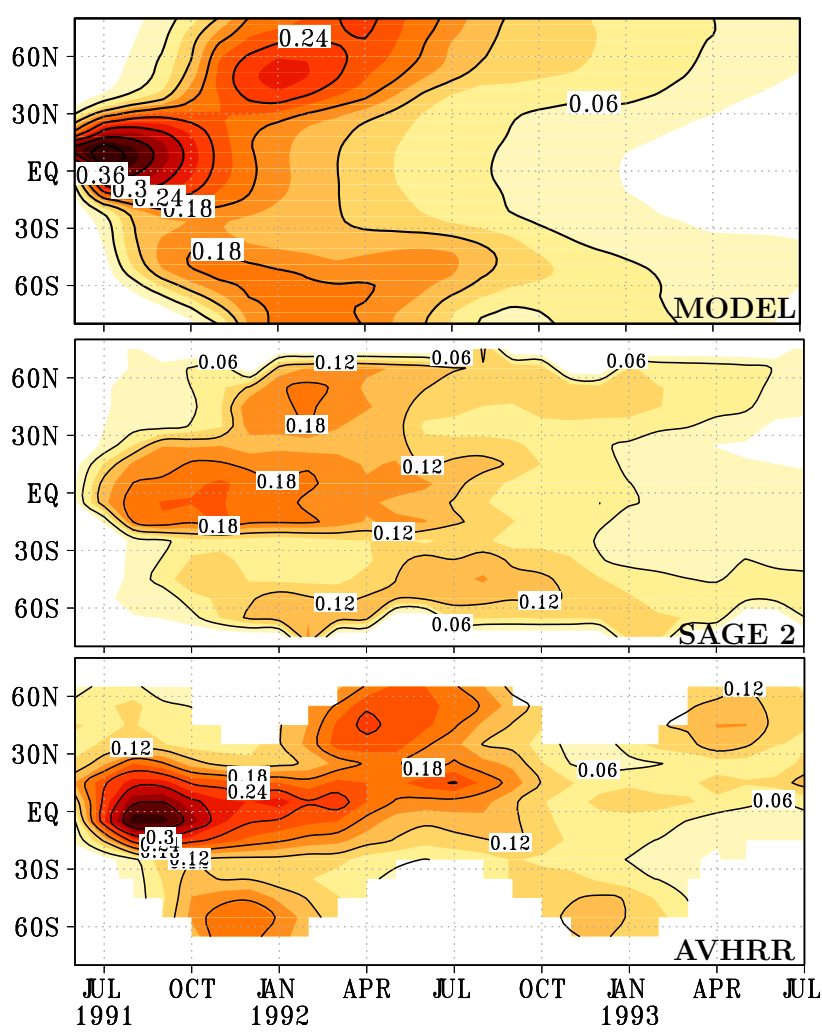

Fig. 4. Aerosol optical depth at $0.55 \mu \mathrm{m}$, model results (top), SAGE2 data (middle) (Thomason et al., 1997), AVHRR data (bottom) (Long and Stowe, 1994).

\section{Impact of fine ash on the radiation budget and its con- sequences for transport of sulfate}

In this section the role of fine ash in the evolution of the volcanic cloud is investigated in more detail. This will be done for a tropical eruption (Pinatubo) and a northern hemispheric high latitude eruption (Katmai). For both we assume the strength of one and ten times the strength of the Pinatubo eruption.We also briefly estimate the impact of season due to different flow pattern and radiative conditions. Because of the relatively large particle radius, fine ash has a lifetime of only a few days (Fig. 1). We will therefore concentrate mainly on the first days when the strongest impact can be assumed, but we also investigate longer lasting impacts of fine ash. As this cannot be separated from transport processes, we also describe the evolution of the sulfate cloud. The presented results base each on an ensemble of five members and and differences between simulations with and without are significant. For an easier understanding of the plots, we show significant areas, marked as grey, in some plots only. Significance was calculated following the equations of a ttest.

\subsection{Pinatubo simulation (Pt1_ens)}

The vertically integrated aerosol optical depth of fine ash $\left(\mathrm{AOD}_{A}\right)$ is very high in the first days after the eruption (Fig. 5). Values above $\mathrm{AOD}_{A}=7$ during the first day and 0.75 two days later are far above the values for sulfate. $\mathrm{AOD}_{A}$ decreases fast. After ten days the maximum $\mathrm{AOD}_{A}$ is $0.14,0.03$ after 20 days and 0.012 after 30 days, when the global fine ash concentration decreases to $0.6 \%$ of the emitted $100 \mathrm{Mt}$. Small amounts of fine ash stay even longer in the stratosphere and deposition of fine ash occurs globally still six months after the eruption.

The ash increased total $\mathrm{AOD}_{A}$ is causing an additional cooling at noon at the surface compared to a simulation with sulfate only. The air temperature $2 \mathrm{~m}$ above the surface $(2 \mathrm{~m}$ temperature) drops by one to two degrees over Indochina and India (Fig. 5, bottom) at noon local time (06:00 $\mathrm{h} \mathrm{UTC)}$ in the first three days after the eruption. Negligible influence of the ash particles on the 2-m temperature could be found in our simulations at night. There is not enough fine ash in the troposphere to cause nightly warming by absorption of infrared radiation. 

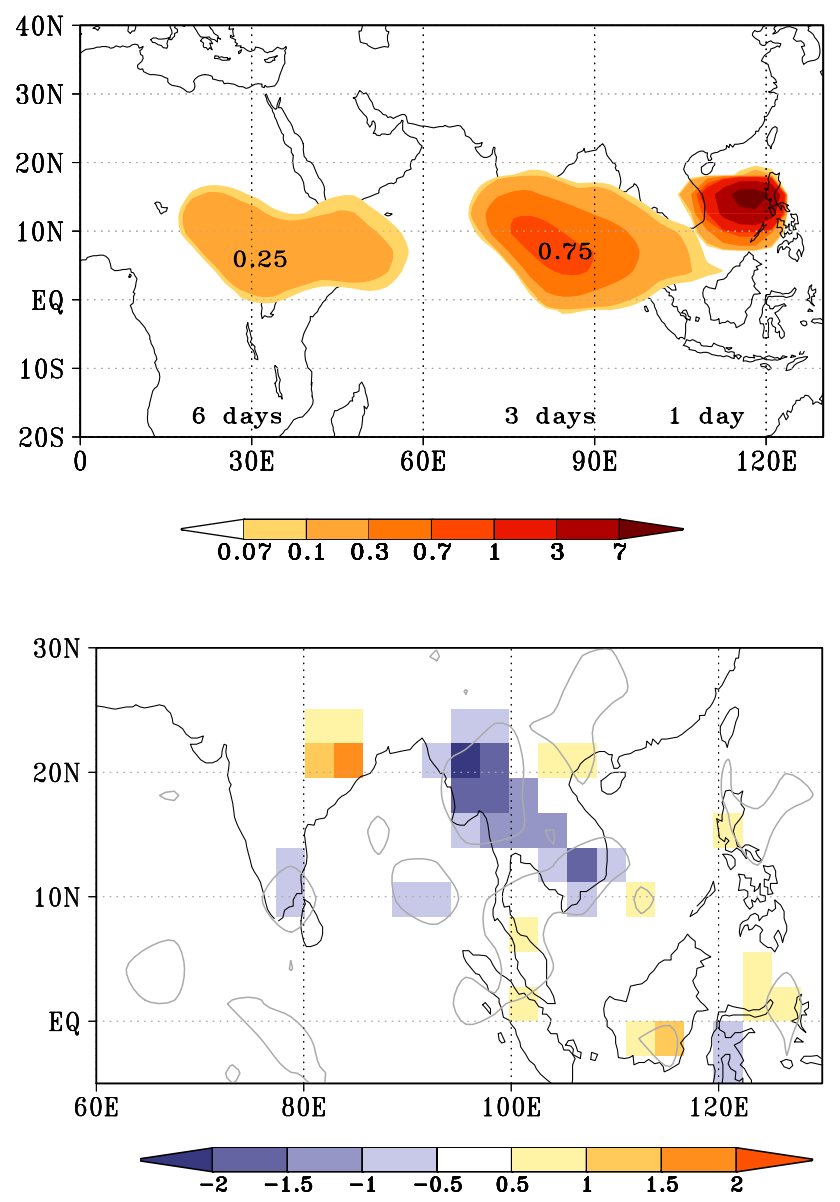

Fig. 5. Development of the aerosol optical depth of fine ash over the first week after the Mt. Pinatubo eruption (top) and differences in the $2 \mathrm{~m}$-temperature $[\mathrm{K}]$ comparing the simulation with and without ash (bottom) at the 3rd day after the eruption at noon local time (Case Pt1_ens). The grey line denotes the 99\% significance level.

Figure 6 shows the daily averaged total radiative heating rates resulting from a simulation with fine ash (left) and without fine ash (right). They are calculated in the model via a twofold calculation of the radiation: once with all aerosols and once under clear sky conditions. Being initialised at a lower vertical level than $\mathrm{SO}_{2}$, two days after the eruption the heated ash cloud can be seen between $50 \mathrm{hPa}$ and $100 \mathrm{hPa}$, with maximum heating rates slightly above $20 \mathrm{~K} /$ day. The sulfate layer on top of the ash is cooled, up to $-10 \mathrm{~K} /$ day by outgoing long-wave radiation, in both simulations. Values differ strongly between day and night. Especially in the first two days when the cloud is very dense, cooling at night $(-15 \mathrm{~K} / \mathrm{d})$ is very effective, overwhelming SW heating $(+5 \mathrm{~K} / \mathrm{d})$ during the day in the daily mean. Also the positive heating rates below the sulfate layer are caused mainly by long-wave radiation effects. The fine ash underneath increases the cooling by long-wave radiation, similar as a

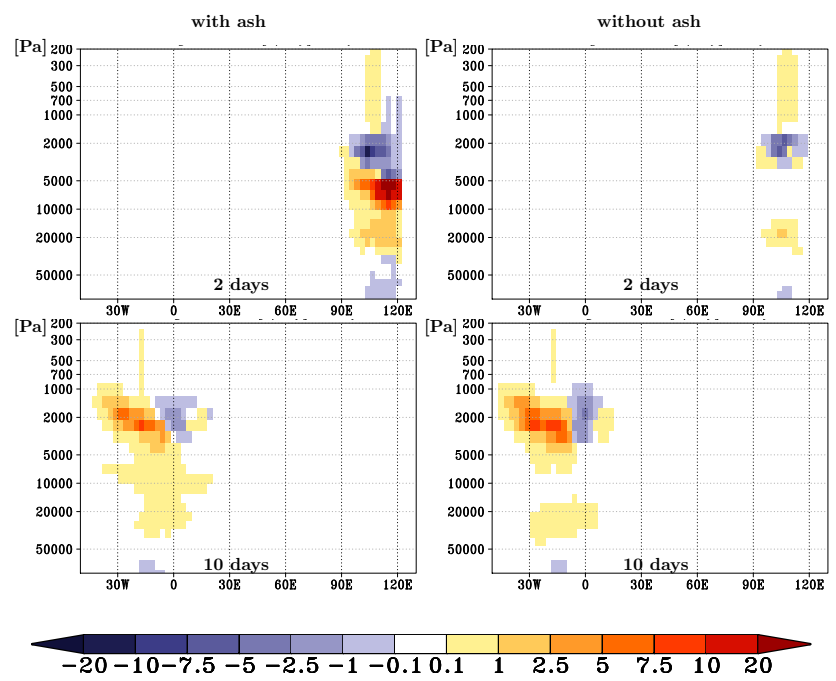

Fig. 6. Total radiative heating rates $[\mathrm{K} / \mathrm{day}]$ as a daily mean two days (top) and ten days (bottom) after the Mt. Pinatubo eruption in a simulation including fine ash (left) and without fine ash (right). A vertical cross section along $15^{\circ} \mathrm{N}$ is shown. (Case Pt1_ens)

strong cirrus cloud would do. The strong cooling effect of the sulfate is turned towards a warming when dispersion decreases the sulfate concentration. With ongoing $\mathrm{SO}_{2}$ oxidation the amount of sulfate increases and at day 10 the cloud is heated due to increasing effective radius of the particles, decreasing AOD, and sedimentation of ash. The effective radius of sulfate increases from $0.3 \mu \mathrm{m}$ in the first days after the eruption to $0.45 \mu \mathrm{m}$ after 5 days and $0.55 \mu \mathrm{m}$ after 10 days. When the fine ash is mainly sedimented after 10 days, only small differences in the cloud position can be seen, but still slightly less warming occurs underneath the sulfate cloud.

The presented simulations do not account for the UV and IR $\mathrm{SO}_{2}$ absorption. Lary et al. (1994) calculated radiative heating rates of $\max 1.5 \mathrm{~K} / \mathrm{d}$ for $\mathrm{SO}_{2}$, Gerstell et al. (1995) of $2 \mathrm{~K} /$ day. The conversion of $\mathrm{SO}_{2}$ to sulfate takes place in the volcanic cloud and the two species are mixed and co-located. Therefore, we would expect a locally enhanced (over the sulfate) heating effect due to $\mathrm{SO}_{2}$. Anyhow, the radiative impact of ash is much stronger (daily heating of $>20 \mathrm{~K}$ ) dominating the radiative impact.

The influence of fine ash on the transport of the sulfur cloud is illustrated in Fig. 7. Here we give sulfur $(S)$ to include the conversion of $\mathrm{SO}_{2}$ to sulfate. The outer line represents a sulfur concentration of $2.5 \times 10^{-4} \mathrm{~kg}(\mathrm{~S}) / \mathrm{kg}$, the inner one varies to give an impression of the location of the maximum values. The differences between both simulations are small and within the $99 \%$ significance level. Six days after the eruption the cloud containing fine ash (blue line) shows a slightly increased transport towards the south and after 20 days (Fig. 7, bottom) the ash containing cloud is transported around the globe slightly quicker than without 

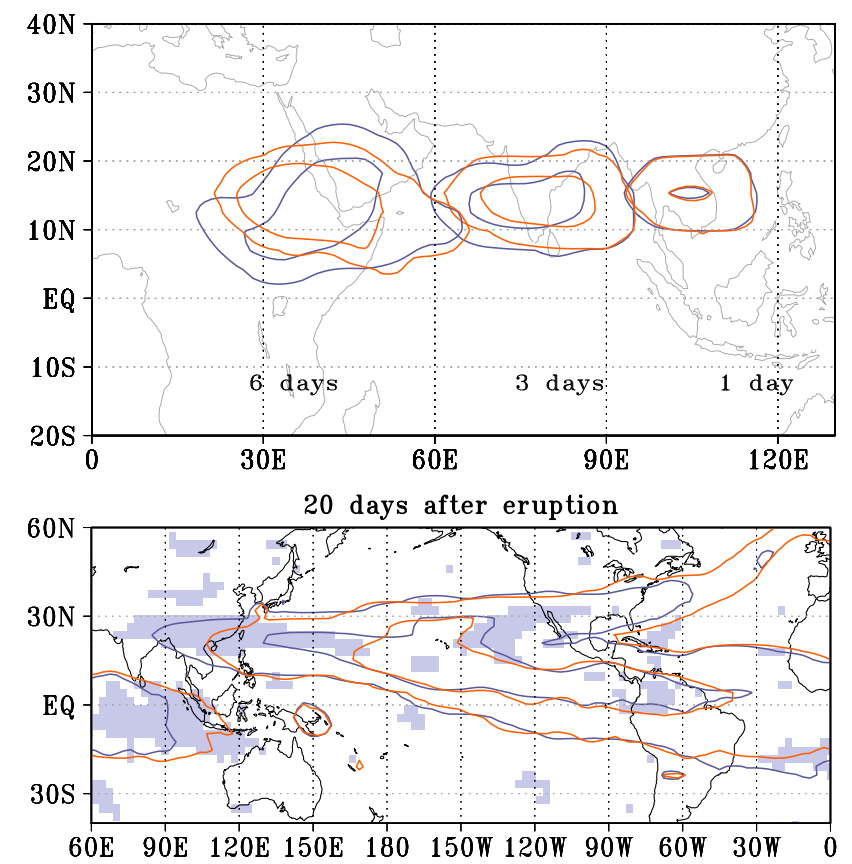

Fig. 7. Distribution of sulfur burden $\left(\mathrm{SO}_{2}+\mathrm{SO}_{4}^{2-}\right)$ in a simulation excluding (orange) and including (blue) fine volcanic ash. Top: Sulfur at 12:00 GMT one, three and six days after the eruption. The outer concentration line represents $2.5 \times 10^{-4} \mathrm{~kg}(\mathrm{~S}) / \mathrm{m}^{2}$, the inner line has different concentrations on the different days, to mark the position of the cloud maximum. Bottom: Distribution of sulfur 20 days after the eruption. The outer concentration line represents $5 \times 10^{-6} \mathrm{~kg}(\mathrm{~S}) / \mathrm{m}^{2}$. Areas shaded grey denote significance levels above $99 \%$. Differences between the two cases in the top figure are significant as well. (Case Pt1_ens)

ash. Radiatively heated air expands, causing disturbances in the flow pattern. These disturbances differ for the cases with and without ash, resulting in varying dispersion and transport of the cloud.

\subsection{0 times Pinatubo (Pt10_ens)}

We performed a sensitivity study applying ten times higher emissions to a Pinatubo eruption scenario (date, location, and emission rate of the eruption are those of Pinatubo) to see the influence of the emission strength on the impact of the fine ash. We obtain a 4 times higher total $\mathrm{AOD}_{A}$ for this scenario in the first days after the eruption (Fig. 8, top). The prescribed particle size distribution for fine ash emissions caused this linear response. The $\mathrm{AOD}_{A}$ rapidly decreases in the following days to values of 0.3810 days after the eruption, 0.09 after 20 days, 0.035 after 30 days.

The maximum heating rates are increased compared to PT1 by a factor of two (Fig. 9), two days after the eruption and fine ash causes strong positive heating rates below the sulfate cloud. The additional heating of fine ash
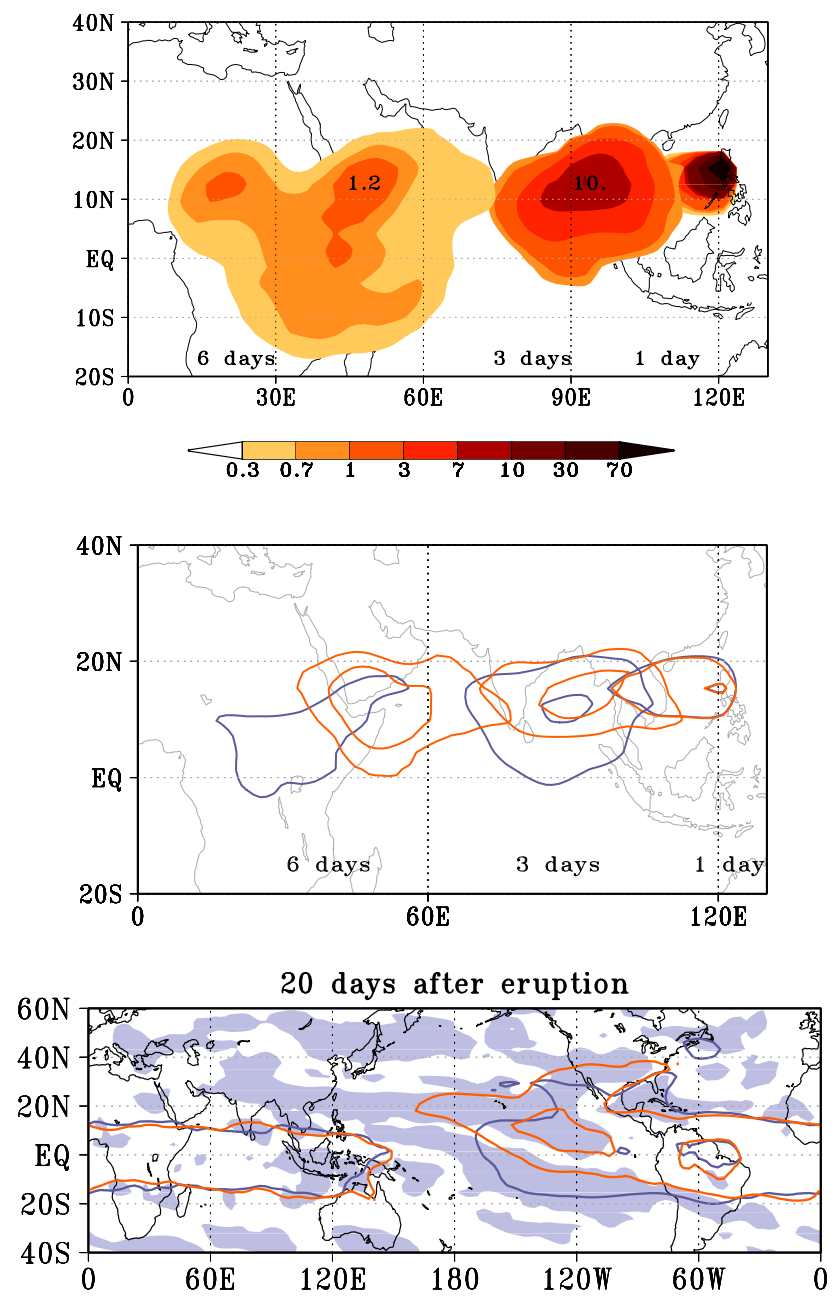

Fig. 8. Top: Development of the aerosol optical depth of fine ash over the first week after the Mt Pinatubo eruption (Case Pt10_ens). Middle and bottom: Distribution of sulfur burden $\left(\mathrm{SO}_{2}+\mathrm{SO}_{4}^{2-}\right)$ in a simulation excluding (orange) and including (blue) fine volcanic ash. Middle: Sulfur at 12:00 GMT one, three and six days after the eruption. The outer concentration line represents $4 \times 10^{-3} \mathrm{~kg}(\mathrm{~S}) / \mathrm{m}^{2}$, the inner one has different concentrations on the different days, to mark the position of the cloud maximum. Differences are significant. Bottom: The distribution of sulfur 20 days after the eruption. The outer concentration line represents $2 \times 10^{-4} \mathrm{~kg}(\mathrm{~S}) / \mathrm{m}^{2}$. Differences are significant in the grey shaded areas. Differences between the two cases in the moddle figure are significant as well. (Case Pt10_ens)

in the first two to three days after the eruption causes a stronger dispersion and an increased horizontal extension of the cloud. Therefore, the cloud without ash is more compact and stronger cooled and heated by radiative heating processes ten days after the eruption.

Compared to the non-ash case the $2 \mathrm{~m}$-temperature is reduced by more than $3 \mathrm{~K}$ over Indochina two days after the 

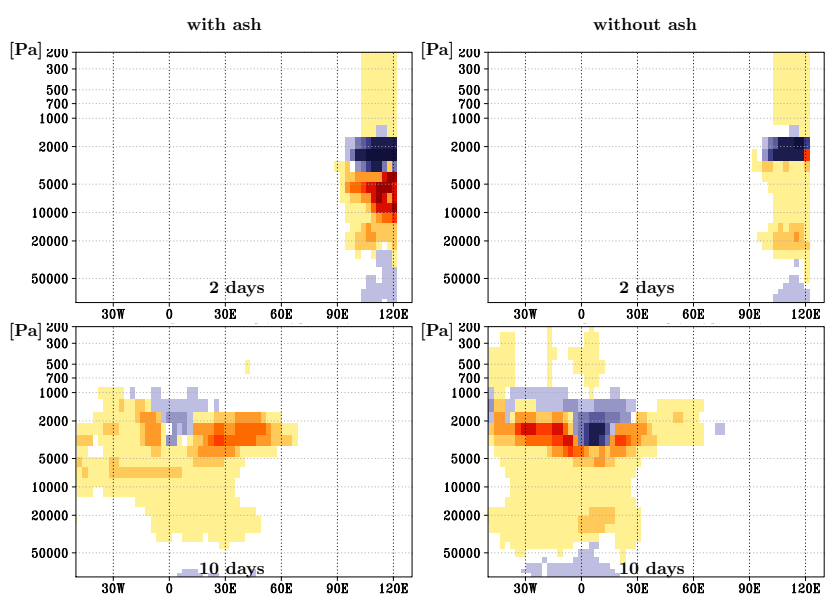

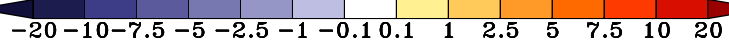

Fig. 9. Heating rates [K/day] two days (top), five days (middle), and ten days (bottom) after the eruption in a simulation including ash (left) and without ash (right). Given is a vertical cross section along $15^{\circ}$ N. (Case Pt10_ens)

eruption, and after three days also over India and Central Africa by 1 to $3 \mathrm{~K}$ cooler temperatures are simulated ${ }^{2}$.

Figure 8 (middle) shows the sulfur burden for the 10 times Pinatubo simulations with and without fine ash. Both clouds are at the same location shortly after the eruption and differ stronger the following days. In radiatively heated areas the expanding air causes outflows (Fig. 10), in cooled areas we see an inflow. The ash containing cloud is stronger heated in the first days and dispersion of the cloud increases (Fig. 8, middle, 3rd day). Six days after the eruption the ash containing cloud is transported about $3000 \mathrm{~km}$ farther to the west. The cloud without ash is more compact and stabilised by a small vortex in the area of the strongest heating (Fig. 10, bottom, $20^{\circ} \mathrm{N}, 50^{\circ} \mathrm{E}$ ). The Coriolis force causes a right turn of the expanding air. The vortex is stable for about two days. With ash, the heating in the further dispersed cloud is not sufficient to cause a rotation of expanding air even there are rotational movements in the vicinity of the volcanic cloud. The impact of the vortex diminishes with time and 20 days after the eruption the sulfur clouds show only small differences in their location (Fig. 8, bottom). The northward shift in cloud position is caused by a slight vertical uplift of the cloud without ash into another wind regime.

\subsection{Katmai simulation (Kat1_ens)}

Comparing wind patterns of several years taken from a climatological MAECHAM5 simulation, the typical meteorological situation in Southern Alaska, the area of the Mt. Katmai volcano, is determined by a strong vertical wind shear in

\footnotetext{
${ }^{2}$ The cooling is only seen over land as we used prescribed SSTs.
}

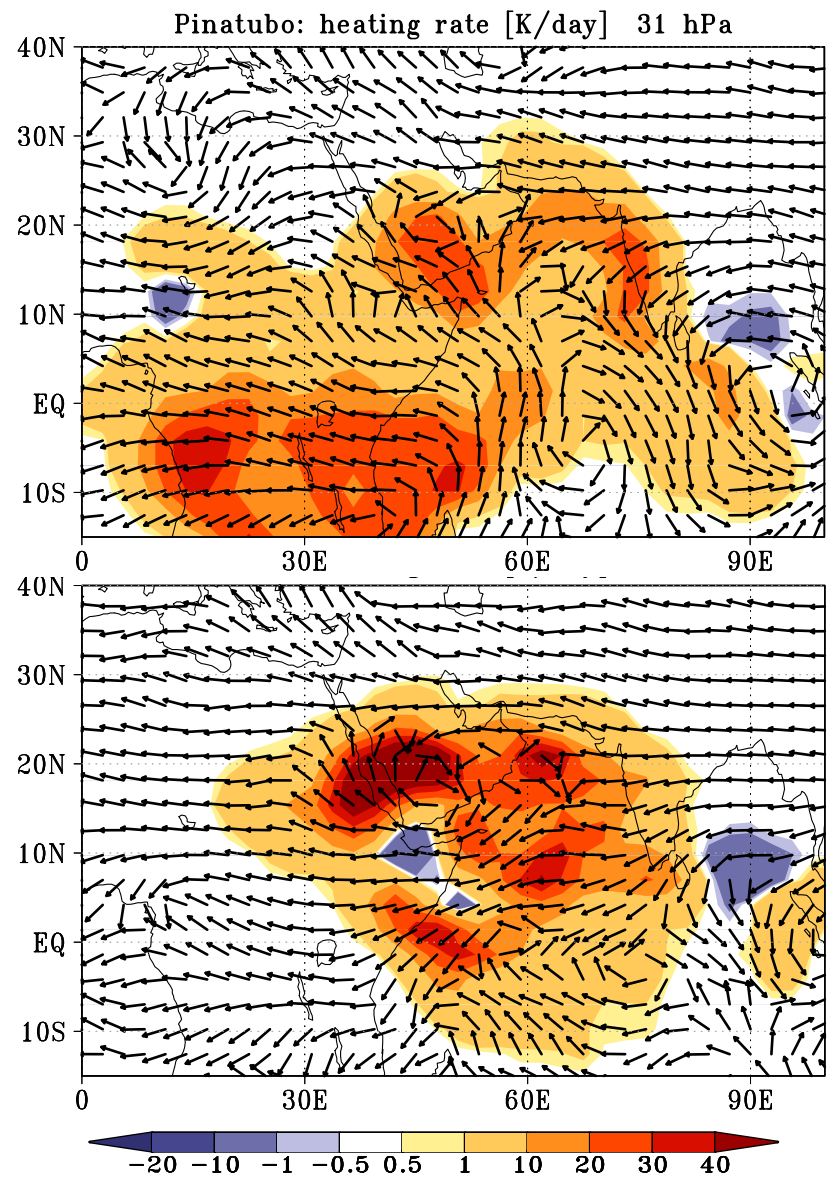

Fig. 10. Wind pattern and heating rates [K/day] at $31 \mathrm{hPa}$ in the simulation containing ash (top) and without ash (bottom) (Pt10_ens).

the stratosphere in June. South-westerly to north-westerly winds are prevailing in the lower stratosphere, turning to south-easterly to northeasterly winds above $50 \mathrm{hPa}$ and easterly above $25 \mathrm{hPa}$. This general pattern can be disturbed by cyclones, causing variations between more northerly and southerly wind directions influencing the prevailing easterly or westerly flow. The mean wind speed is below $10 \mathrm{~m} / \mathrm{s}$, much lower than in the tropics.

Figure 11 (bottom) shows the aerosol optical depth of ash. $\mathrm{AOD}_{\mathrm{A}}$ values maintain high during the first week which is related to low dispersion of the cloud and low stratospheric wind speeds. This figure indicates also the transport of fine volcanic ash along the northern coast of Alaska towards Canada. The ash is emitted at $50 \mathrm{hPa}$ and sedimented quickly to lower levels. It is therefore affected by the south-westerly winds. In contrast, Figure 11 (top) shows that the $\mathrm{SO}_{2}$ cloud, being injected into the level above $30 \mathrm{hPa}$, is transported towards Siberia. During the first 5 days differences between the simulations with and without ash are small. After 5 days the wind-shear clearly separates fine ash and sulfur due to 

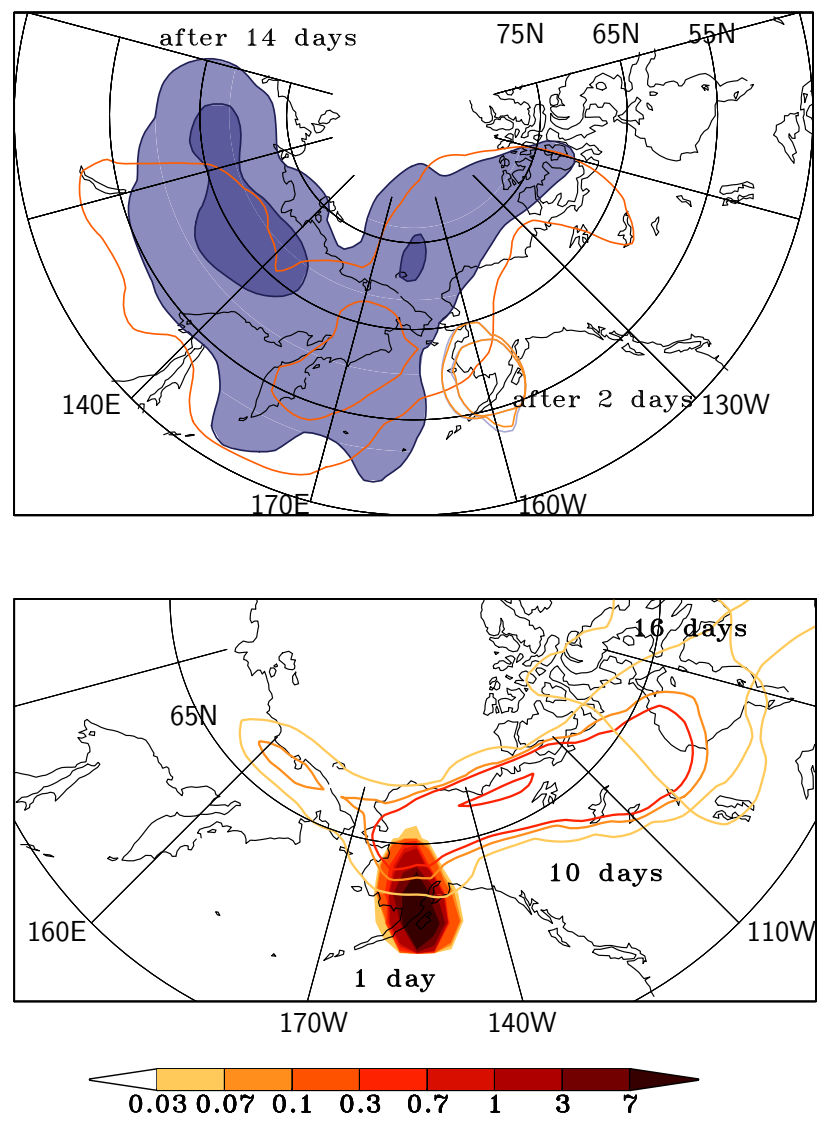

Fig. 11. Top: Distribution of sulfur burden $\left(\mathrm{SO}_{2}+\mathrm{SO}_{4}^{2-}\right)$ two and 14 days after the eruption in a simulation excluding (orange) and including (blue) fine volcanic ash as mean of a five simulations ensemble. The outer concentration line represents $0.0001 \mathrm{~kg}(\mathrm{~S}) / \mathrm{m}^{2}$, the inner line $0.001 \mathrm{~kg}(\mathrm{~S}) / \mathrm{m}^{2}$.

Bottom: Development of the aerosol optical depth of fine ash over the first week after the eruption at Mt. Katmai. (Case Kat1_ens)

changing transport directions in different levels. The ash is transported to the east. The centre of the sulfate cloud is transported farther northwestward in the simulation with ash and is dispersed over a larger area. The $2 \mathrm{~m}$-temperature is two degrees lower than in the simulation without ash in a small area close to the volcano.

Values of daily heating rates in simulation Kat1_ens (Fig. 12) are in a similar range as PT1. The heated westward drifting ash cloud can still be seen after 10 days east of $150^{\circ} \mathrm{W}$. As ash and sulfate are separated, the heating rates for the sulfate cloud are quite similar in both simulations. Variations are mainly caused by the different transport direction of the sulfate clouds. In order to capture the main impact of the heating rates, the cross sections in Fig. 12 were taken at increasing latitudes.

In general, the volcanic cloud stays close to the origin. This is caused by low wind speeds, as well as by the develop-
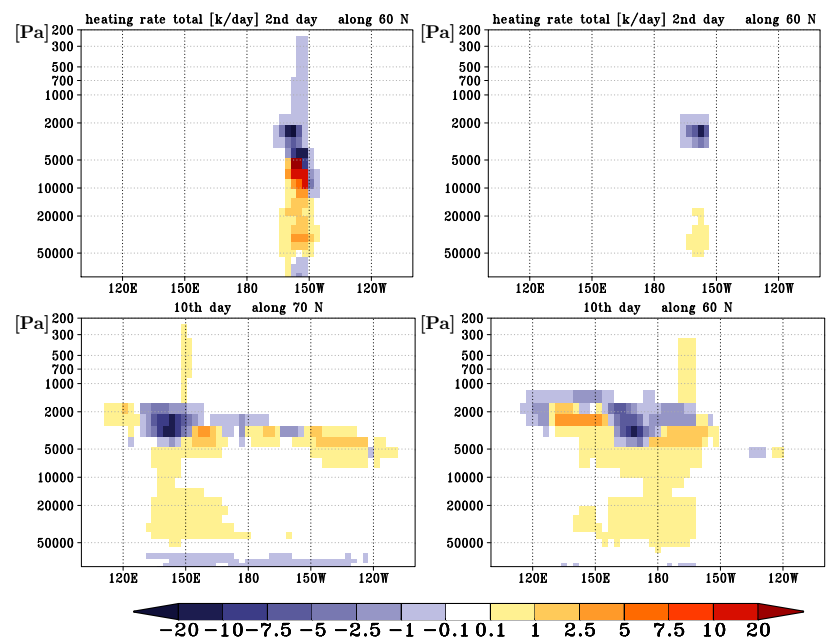

Fig. 12. Total heating rates $[\mathrm{K} /$ day $]$ as a daily mean two days (top) and ten days (bottom) after the Mt. Katmai eruption in a simulation including ash (left) and without ash (right). Given is a vertical cross section along $60^{\circ} \mathrm{N}$ and $70^{\circ} \mathrm{N}$, the latitudes where the maximum concentration is located. (Case Kat1_ens)

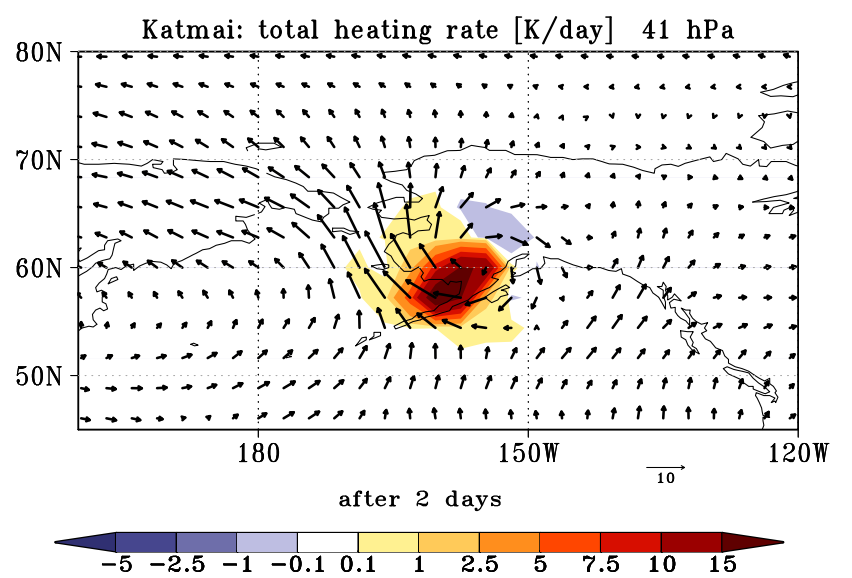

Fig. 13. Radiative heating [K/day] and wind vectors at $41 \mathrm{hPa}, 36 \mathrm{~h}$ after the eruption showing the rotation of the cloud in the simulation with ash (Kat1_ens).

ment of a rotational movement inside of the volcanic cloud starting about two days after the eruption (Fig. 13). A difference to the Pt10_ens case is a weaker stratospheric main flow and a stronger Coriolis force. Thus, the impact of the heated ash cloud causes an early development of a vortex in the ash containing level. The rotating cloud is slowly advected with the main wind. Due to the lower dispersion the cloud is very dense and outgoing long-wave radiation is dominating the radiative processes even longer than in PT1_ens.

The radiative heating and cooling of the volcanic cloud are causing vertical movements inside the cloud. Solar heating 

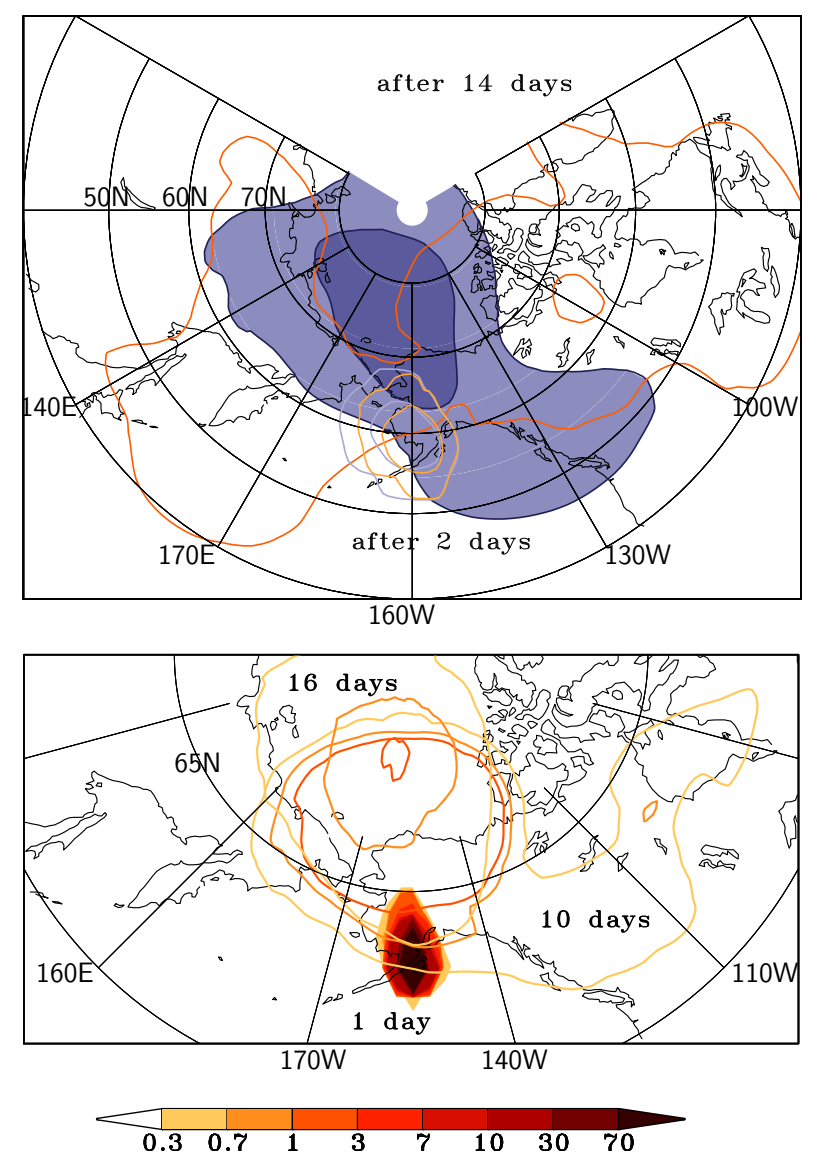

Fig. 14. Top: Distribution of sulfur burden $\left(\mathrm{SO}_{2}+\mathrm{SO}_{4}^{2-}\right)$ two and 14 days after the eruption in a simulation excluding (orange) and including (blue) volcanic ash. The outer concentration line represents $0.001 \mathrm{~kg}(\mathrm{~S}) / \mathrm{m}^{2}$.

Bottom: Aerosol optical depth of fine ash one, 10 and 16 days after the eruption. (Case Kat10_ens)

during the day causes a rising of the cloud, partly compensating ash sedimentation. In the simulation without ash the effects of these vertical movements are much smaller.

\subsection{0 times Katmai (Kat10_ens)}

Increasing the emissions at the Katmai volcano to $10 \times$ Pinatubo increases the radiative heating of the cloud causing an intensified rotation of the cloud. Figure 14 (top) shows the sulfur clouds with and without fine ash two weeks after the eruption. The cloud containing ash is advected about $1500 \mathrm{~km}$ to the north in 14 days, which is a very short transport distance compared to the previous results Pt1_ens, Pt10_ens and Kat1_ens. The increased amount of volcanic aerosol that can be heated by long and shortwave absorption, stabilises the rotation of the cloud and keeps it much longer active, inhibiting the exchange with the surrounding flow. Seven days after the eruption the radiative forcing in the centre of the cloud is still large $(15 \mathrm{~K} /$ day) and the wind velocity in the rotating cloud is almost twice as high as without ash. The extension of the vortex containing ash is larger in horizontal and vertical direction. Five days later, with ash the wind speed in the vortex is still similar but the non ash containing vortex broke down already.

The rotating volcanic cloud changes also the transport and lifetime of the ash. Figure 14 (bottom) shows the $\mathrm{AOD}_{\mathrm{A}}$ of ash 1,10 and 16 days after the eruption with the maximum concentration about 1000 to $2000 \mathrm{~km}$ north of the eruption location. Farther transported are only parts of the ash which have been sedimented to lower vertical heights. The cloud remains more compact compared to the Pinatubo case and therefore the $\mathrm{AOD}_{\mathrm{A}}$ of the ash is higher for the first twenty days, causing a stronger heating and increased impact of the ash.

\subsection{Impact of fine ash in a winter eruption}

The tropospheric meteorological conditions in the South Asian region change from summer monsoon with mainly south-westerly winds to winter monsoon with north-easterly winds. In the stratosphere in summer over the Asian continent easterly winds dominate and westerly winds in winter are prevalent. The easterly winds in the equatorial region are much weaker in winter. Therefore, after an assumed winter eruption of Mt. Pinatubo, we see a slow westerly transport of the volcanic cloud (Fig. 15). Six days after the eruption the volcanic cloud is over the Bay of Bengal, whereas after six days it is over Africa in the summer case. Additionally, parts of the cloud enter the westerly winds north of $20^{\circ} \mathrm{N}$ and are transport eastward via North America and Europe (Fig. 15, bottom). 20 days after the eruption the centre of the volcanic cloud still remains over the northern Indian Ocean. Due to a slight wind-shear, the ash cloud is transported north-westward and six days after the eruption stretches from Northern India to Southern China with the centre over South-East China. Therefore, in this winter case the ash separates further from the sulfate cloud than in summer. Hence, this simulation indicates quite a different transport pattern in winter. However, these differences in the general flow pattern do not change our conclusion on the impact of ash. The heating rates are increased due to ash, causing a slightly stronger winds and westerly transport of the volcanic cloud. The changing horizontal wind direction from easterly to westerly winds between $10^{\circ} \mathrm{N}$ and $20^{\circ} \mathrm{N}$ assist the temporary development of areas with anti-cyclonic rotation in the ash containing cloud, keeping the cloud more condense. The overall impact of the ash is similar to the summer case and the main transport of the cloud without ash does not differ strongly from the pattern with ash.

The situation is different in the more northern latitudes. In a winter eruption of Mt. Katmai the ash has almost no impact due to the short daytime length and the low heating rates. The volcanic cloud is transported fast towards the central North 

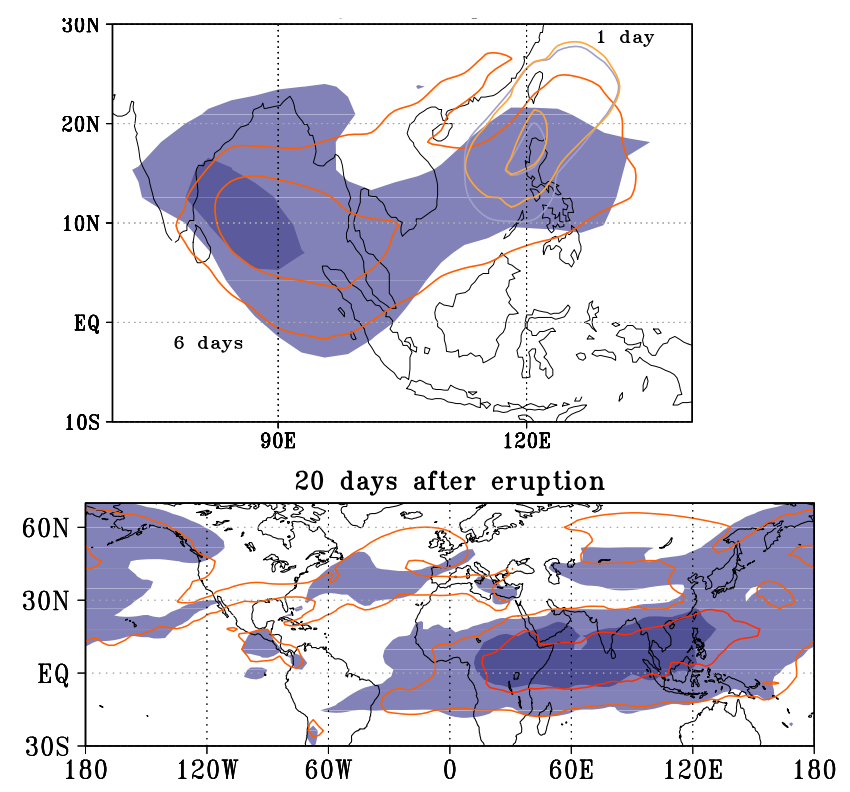

Fig. 15. Distribution of sulfur burden $\left(\mathrm{SO}_{2}+\mathrm{SO}_{4}^{2-}\right)$ in a winter eruption simulation excluding (orange) and including (blue) fine volcanic ash. Top: Sulfur at 12:00 GMT one, three and six days after the eruption. The outer concentration line represents $2.5 \times 10^{-4} \mathrm{~kg}(\mathrm{~S}) / \mathrm{m}^{2}$, the inner line has different concentrations on the different days, to mark the position of the cloud maximum. Bottom: Distribution of sulfur twenty days after the eruption. The outer concentration line represents $5 \times 10^{-6} \mathrm{~kg}(\mathrm{~S}) / \mathrm{m}^{2}$. (Case Pt1w_ens)

American continent and no rotation of the cloud slows this transport. This again indicates the importance of the radiative heating on the transport of the volcanic cloud in case of a large eruption.

\subsection{Influence of QBO}

A further process, strongly influencing transport processes in the tropical stratosphere is the QBO. In our simulations we used the MAECHAM5 model with 39 vertical levels. This model version has no QBO in the free-running setup, which could only be obtained by nudging of equatorial stratospheric winds (Giorgetta and Bengtsson, 1999). In the applied model setup easterly winds are calculated per definition in the stratosphere, which agrees well with the easterly QBO phase during the June 1991 Pinatubo eruption. The opposite westerly QBO phase differs not only in the horizontal wind direction, but also sinking and rising processes are changed. Punge et al. (2009) simulated the QBO effect on stratospheric long range transport, showing changes mainly during the transition between phases of the QBO. Anyhow, these processes are slow compared to the lifetime of fine ash particle in the stratosphere. We therefore expect a similar impact of ash as in the described simulations and dispense to set up additional sensitivity experiments with respect to the QBO.

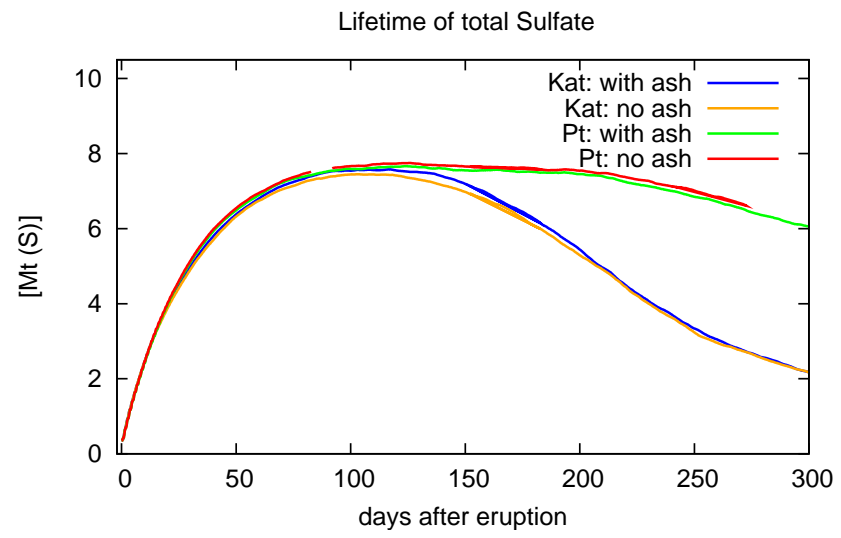

Fig. 16. Global total sulfate concentration $\mathrm{kg}(\mathrm{S}) / \mathrm{kg}$ for 300 days after the eruption in the simulation Pt1 and Kat1.

\subsection{Impact of fine ash on sulfate evolution}

Figure 16 shows a comparison of total global sulfate concentration of simulation Pt1 and Kat1, both with and without fine ash. The long-term impact of the fine ash is small. The sulfate concentrations differ by less than one percent whether ash is included or not. The sulfate particle radius is very similar in Pt1 between the ash and non-ash case. In Kat1 the effective radius differs between 0.05 and $0.1 \mu \mathrm{m}$ and is smaller in the simulation with ash in the first three months. The particle radius depends on the sulfur concentration which at the higher northern latitudes differs stronger locally between an ash and non-ash simulation. However, we did not take into account any heterogeneous nucleation of sulfuric acid and water on the fine ash particles. Similar to dust, coated fine ash particles might act as sink via condensation and coagulation and therefore modify the aerosol size distribution (Korhonen et al., 2003).

The lifetime of sulfate is shorter after the Alaskan eruption compared to the sulfate lifetime after the eruption of Mt. Pinatubo. Here the Brewer-Dobson-circulation with downward transport at high Northern latitudes plays a role. The sulfate cloud is not advected over both hemispheres, causing higher sulfate concentrations and increased particle growth than after a tropical eruption. The larger effective radius, about $0.15 \mu \mathrm{m}$ as a zonal mean value, increases the sedimentation. On the other hand, the longer polar day and thus longer active $\mathrm{OH}$ chemistry does not have an effect on the lifetime of $\mathrm{SO}_{2}$.

\section{Conclusions}

The simulated evolution of the sulfur and fine ash aerosol cloud after the eruption of Mt. Pinatubo was compared to satellite and lidar measurements. Overall, measurements and simulation results agree very well for the aerosol optical 
depth and effective radius of the particle, even though differences can be seen in some details. The particle radius strongly determines the sedimentation and therefore the lifetime of sulfate aerosol in the stratosphere. The particle radius is in the upper range of the measurements, causing a return to pre-eruption values about 6 months earlier than observed. The AOD of sulfate shows compared to measurements qualitatively and quantitatively very good results.

The influence of fine volcanic ash on the climatic impact of a volcanic eruption is small. The lifetime of ash is too short to have an influence itself and the long-term impact of the ash via sulfate particle radii and concentration, caused by different $\mathrm{SO}_{2}$ concentration in the early phase after the eruption, is negligible. Changes in the global sulfate concentration due to the presence of fine ash are below one percent.

However, in the first two weeks after the eruption, fine ash is important as the ash changes the surface temperature and the wind pattern in the vicinity of the cloud. This impact depends on the strength of the undisturbed stratospheric wind. It is smaller in the tropics where the wind velocity is higher than at higher latitudes.

Volcanic fine ash with a size smaller than $15 \mu \mathrm{m}$ has a lifetime of a few days to weeks in the stratosphere, causing the main impact during the first days after the eruption. Fine ash is normally placed underneath the $\mathrm{SO}_{2}$ cloud and an additional radiative heating below the sulfate cloud is found in this period. This heating causes strong disturbances in flow pattern, changing wind direction and increasing wind speed. The impact of this additional motion strongly depends on the location, time and strength of the eruption. At the surface the $2 \mathrm{~m}$-temperature is further decreased by about $2 \mathrm{~K}$ due to the additional ash in the first three days.

In the tropics, the local impact of the additional radiative heating of the fine ash is too weak to interfere with the prevailing easterlies in a QBO east phase and monsoon winds. In the $1 \times$ Pinatubo case we see only small impact of fine ash on local winds and on the transport of the volcanic aerosol cloud. In the 10 times stronger eruption case, the ash caused a stronger dispersion and increased advection. Without ash, the volcanic cloud is more compact. Five to six days after the eruption a small vortex further stabilises the cloud and reduces advection, thereby increasing the differences to the ash case.

At $60^{\circ} \mathrm{N}$, at the position of Mt. Katmai, the situation is different, because the local flow is weaker and the CoriolisForce is stronger. The latter causes a clockwise rotation of the aerosol cloud due to expanding heated air. Due to this rotation the volcanic cloud is less dependent on the surrounding flow, stays closer to the origin and horizontal dispersion is reduced. The ash causes an vertical expansion of the heated area also below the sulfate cloud, which increases the vertical extension of the rotating mass. Due to increased uplifting of the sulfate and changing wind direction with height, together with increased wind speed, the transport direction of the sulfate cloud changes due to the presence of fine ash.
The described interaction between regional wind field and the volcanic aerosol occurs via radiative heating. The radiative heating of the aerosol has a strong impact on the behaviour of the cloud, e.g., by inducing vertical motion and horizontal expansion. Radiative heating induced rotation of the cloud diminishes advection. This reduced transport of ash has also impact on location and pattern of ash fall deposits. Without radiative heating processes, the regional wind fields are not influenced by the volcanic cloud, and in case of large eruptions the model could not correctly simulate the transport and sedimentation of ash nor the long-range transport of the sulfate cloud (Timmreck and Graf, 2006). Therefore, the coupling of the aerosol with solar and terrestrial radiation is necessary. The simulation of ash and sulfate is important when studying the short term impacts of a large volcanic eruption cloud reaching the stratosphere.

Acknowledgements. This work contributed to the Super Volcano project at the Max-Planck Institute for Meteorology. U. Niemeier is partially supported by SCOUT-O3 and CLISAP. C. Timmreck acknowledges founding from the German Science Foundation DFG grant TI 344/1-1. We further thank Rene Hommel, Jan Kazil, Harri Kokkola and Hanna Vehkamäki for their help to modify HAM. We thank also two anonymous referees and Ingo Kirchner for helping to improve the manuscript.

The service charges for this open access publication have been covered by the Max Planck Society.

Edited by: M. Dameris

\section{References}

Ansmann, A., Mattis, I., Wandinger, U., Wagner, F., Reichardt, J., and Deshler, T.: Evolution of the Pinatubo Aerosol: Raman Lidar Observations of Particle Optical Depth, Effective radius, Mass, and Surface Area over Central Europe at 53.4 N, J. Atmos. Sci., 54, 2630-2641, 1997.

Baines, P. G., Jones, M. T., and Sparks, R. S. J.: The variation of large-magnitude volcanic ash cloud formation with source latitude, J. Geophys. Res., 113, D21204, doi:10.1029/ 2007JD009568, 2008.

Baran, A. J. and Foot, J. S.: New application of the operational sounder HIRS in determining a climatology of sulphuric acid aerosol from the Pinatubo eruption, J. Geophys. Res., 99, 673679, 1994.

Bluth, G. J. S., Doiron, S. D., Schnetzler, C. C., Krueger, A. J., and Walte, L. S.: Global tracking of the $\mathrm{SO}_{2}$ clouds from the June, 1991 Mount Pinatubo eruptions, Geophys. Res. Lett., 19, 151154, 1992.

Chakraborty, P., Gioia, G., and Kieffer, S. W.: Volcanic mesocyclones, Nature, 458, 497-500, doi:10.1038/nature07866, 2009.

Duggen, S., Croot, P., Schacht, U., and Hoffmann, L.: Subduction zone volcanic ash can fertilise the surface ocean and stimulate phytoplankton growth: Evidence from biogeochemical experiments and satellite data, Geophys. Res. Lett., 34, L01612, doi: 10.1029/2006GL027522, 2007. 
Feichter, J., Kjellstrom, E., Rohde, H., Dentener, F., Lelieveld, J., and Roelofs, G. J.: Simulation of the tropospheric sulfur cycle in a global climate model, Atmos. Environ., 30, 1693-1707, 1996.

Fero, J., Carey, S. N., and Merrill, J. T.: Simulation of the 1980 eruption of Mount St. Helens using the ash-tracking model PUFF, J. Volcanol. Geotherm. Res., 175, 355-366, doi:10.1016/ j.jvolgeores.2008.03.029, 2008.

Folch, A., Jorba, O., and Viramonte, J.: Volcanic ash forecast - application to the May 2008 Chaitén eruption, Nat. Hazards Earth Syst. Sci., 8, 927-940,, 2008.

Gerstell, M., Crisp, J., and Crisp, D.: Radiative Forcing of the Stratosphere by SO2 Gas, Silicate Ash, and H2SO4 Aerosols Shortly after the 1982 Eruptions of El Chichón, Journal of Climate, 8, 1060-1070, doi:10.1175/1520-0442(1995)008<1060: RFOTSB $>2.0 . C O ; 2,1995$.

Giorgetta, M. A. and Bengtsson, L.: Potential role of the quasibiennial oscillation in the stratosphere-troposphere exchange as found in water vapor in general circulation model experiments, J. Geophys. Res., 104, 6003-6019, 1999.

Giorgetta, M. A., Manzini, E., Roeckner, E., Esch, M., and Bengtsson, L.: Climatology and forcing of the quasi-biennial oscillation in the MAECHAM5 model, J. Climate, 19, 3882-3901, 2006.

Guo, S., Rose, W. I., Bluth, G. J. S., and Watson, I. M.: Particles in the great Pinatubo volcanic cloud of June 1991: The role of ice, Geochemistry, Geophysics, Geosystems, 5, Q05003, doi:10. 1029/2003GC000655, 2004.

Herzog, M., Graf, H. F., Textor, C., and Oberhuber, J. M.: The effect of phase changes of water on the development of volcanic plumes, J. Volcanol. Geotherm. Res., 87, 55-74, 1998.

Holasek, R. E., Self, S., and Woods, A. W.: Satellite observations and interpretation of the 1991 Mount Pinatubo eruption plumes, J. Geophys. Res., 101(B12), 635-655, 1996a.

Holasek, R. E., Woods, A., and Self, S.: Experiments on gas-ash separation processes in volcanic umbrella clouds, J. Volcanol. Geotherm Res., 70, 169-181, 1996b.

Hommel, R.: Die Variabilität von stratosphärischem HintergrundAerosol. Eine Untersuchung mit dem globalen sektionalen Aerosolmodell MAECHAM5-SAM2., Ph.D. thesis, Universität Hamburg, 2008.

Jäger, H., Uchino, O., Nagai, T., Fujimoto, T., Freudenthaler, V., and Homburg, F.: Ground-based remote sensing of the decay of the Pinatubo eruption cloud at three Northern Hemisphere sites, Geophys. Res. Lett., 22, 607-610, 1995.

Jöckel, P., Sander, R., Kerkweg, A., Tost, H., and Lelieveld, J.: Technical Note: The Modular Earth Submodel System (MESSy) - a new approach towards Earth System Modeling, Atmos. Chem. Phys., 5, 433-444, 2005,

http://www.atmos-chem-phys.net/5/433/2005/.

Jones, M., Sparks, R. S. J., and Valdes, P. J.: The climatic impact of supervolcanic ash blankets, Climate Dynamics, 29, 553-564, doi:10.1007/s00382-007-0248-7, 2007.

Kirchner, I., Stenchikov, G. L., Graf, H.-F., Robock, A., and Antuña, J. C.: Climate model simulation of winter warming and summer cooling following the 1991 Mount Pinatubo volcanic eruption, J. Geophys. Res., 104, 19039-19056, 1999.

Kokkola, H., Hommel, R., Kazil, J., Niemeier, U., Partanen, A.-I., Feichter, J., and Timmreck, C.: Aerosol microphysics modules in the framework of the ECHAM5 climate model - intercomparison under stratospheric conditions, Geoscientific Model Develop- ment, 2, 97-112, http://www.geosci-model-dev.net/2/97/2009/, 2009.

Korhonen, H., Napari, I., Timmreck, C., Vehkamki, H., Pirjola, L., Lehtinen, K., Lauri, A., and Kulmala, M.: Impact of sulphate coating mineral dust on new particle formation: A model study of heterogeneous nucleation, J. Geophys. Res., D20, 8791, doi: 10.1029/2002JD003167, 2003.

Krueger, A. J., Walter, L. S., Bhartia, P. K., Schnetzler, C. C., Krotkov, N. A., Sprod, I., and Bluth, G. J. S.: Volcanic sulfur dioxide measurements from the total ozone mapping spectrometer instrument, J. Geophys. Res., 100, 14057-14076, 1995.

Lary, B., Balluch, M., and Bekki, S.: Solar heating after volcanic eruption: The importance of $\mathrm{SO}_{2}$ absorption, Q. J. Roy. Meteor. Soc., 120, 1683-1688, 1994.

Lin, S. J. and Rood, R. B.: Multidimensional flux form semiLagrangian transport, Mon. Weather Rev., 124, 2046-2068, 1996.

Long, C. and Stowe, L.: Using the NOAA/AVHHR to study stratospheric aerosol optical thickness following the Mt. Pinatubo eruption, Geophys. Res. Lett., 21, 2215-2218, 1994.

Oman, L., Robock, A., Stenchikov, G. L., Thordarson, T., Koch, D., Shindell, D. T., and Gao, C.: Modeling the distribution of the volcanic aerosol cloud from the 1783-1784 Laki eruption, J. Geophys. Res., 111, D12209, doi:10.1029/2005JD006899, 2006.

Pollack, J. R., Toon, O. B., and Khare, B.: Optical Propoerties of Some Terrestrial Rocks and Glasses, Icarus, 19, 372-389, 1973.

Prata, A. J. and Kerkmann, J.: Simultaneous retrieval of volcanic ash and SO2 using MSG-SEVIRI measurements, Geophys. Res. Lett., 34, L05813, doi:10.1029/2006GL028691, 2007.

Punge, H. J., Konopka, P., Giorgetta, M. A., and Müller, R.: Effects of the quasi-biennial oscillation on low-latitude transport in the stratosphere derived from trajectory calculations, J. Geophys. Res., 114, D03102, doi:10.1029/2008JD010518, 2009.

Read, W. G., Froidevaux, L., and Waters, J. W.: Microwave limb sounder measurements of stratospheric $\mathrm{SO}_{2}$ from the Mt. Pinatubo volcano, Geophys. Res. Lett., 20, 1299-1302, 1993.

Roeckner, E., Baeuml, G., Bonaventura, L., Brokopf, R., Esch, M., Giorgetta, M., Hagemann, S., Kirchner, I., Kornblueh, L., Manzini, E., Rhodin, A., Schlese, U., Schulzweida, U., and Tompkins, A.: The atmospheric gernal circulation model ECHAM5 - Part I, MPI Report No. 349, p. 127, 2003.

Russell, P. B., Livingston, J. M., Pueschel, R. F., Pollack, J. B., Brooks, S., Hamill, P., Hughes, J., Thomason, L., Stowe, L., Deshler, T., and Dutton, E.: Global to microscale evolution of the Pinatubo volcanic aerosol, derived from diverse measurements and analyses, J. Geophys. Res., 101, 18745-18763, 1996.

Schneider, D. J., Rose, W. I., Coke, L. R., Bluth, G. J. S., Sprod, I. E., and Krueger, A. J.: Early evolution of a stratospheric volcanic eruption cloud as observed with TOMS and AVHRR, J. Geophys. Res., 104(D4), 4037-4050, doi:10.1029/ 1998JD200073, 1999.

Searcy, C., Dean, K., and Stringer, W.: PUFF: A high-resolution volcanic ash tracking model, J. Volcanol. Geotherm. Res., 80, 1-16, 1998.

Self, S.: The effect and consequences of very large explosive volcanic eruptions, Phil. Trans. R. Soc. A, 364, 2073-2097, doi: 10.1098/rsta.2006.1814, 2006.

Steil, B., Brühl, C., Manzini, E., Crutzen, P. J., Lelieveld, J., 
Rasch, P. J., Roeckner, E., and Krueger, K.: A new interactive chemistry-climate model. 1. Present day climatology and interannual variability of the middle atmosphere using the model and 9 years of HALOE/UARS data., J. Geophys. Res., 108, 4290, doi:10.1029/2002JD002971, 2003.

Stenchikov, G. L., Kirchner, I., Robock, A., Graf, H.-F., Antuña, J. C., Grainger, R. G., Lambert, A., and Thomason, L.: Radiative forcing from the 1991 Mount Pinatubo volcanic eruption, J. Geophys. Res., 103, 13837-13858, 1998.

Stier, P., Feichter, J., Kinne, S., Kloster, S., Vignati, E., Wilson, J., Ganzeveld, L., Tegen, I., Werner, M., Balkanski, Y., Schulz, M., Boucher, O., Minikin, A., and Petzold, A.: The aerosolclimate model ECHAM5-HAM, Atmos. Chem. Phys., 5, 11251156, 2005, http://www.atmos-chem-phys.net/5/1125/2005/.

Suzuki, Y. J. and Koyaguchi, T.: A three-dimensional numerical simulation of spreading umbrella clouds, J. Geophys. Res., 114, B03209, doi:10.1029/2007JB005369, 2009.

Textor, C., Graf, H. F., Herzog, M., Oberhuber, J. M., Rose, W. I., and Ernst, G. G. J.: Volcanic particle aggregation in explosive eruption columnns. Part I: Paramerization of the microphysica of hydrometeors and ash, J. Volcanol Geotherm. Res., 150, 359377, doi:10.1016/j.jvolgeores.2005.09.007, 2006.

Thomas, M. A., Timmreck, C., Giorgetta, M., Graf, H., and Stenchikov, G.: Simulation of the climate impact of Mt. Pinatubo eruption using ECHAM5. Part-I: Sensitivity to the modes of atmospheric circulation and boundary conditions, Atmos. Chem. Phys., 9, 757-769, 2009, http://www.atmos-chem-phys.net/9/757/2009/.

Thomason, L. W., Poole, L. R., and Deshler, T.: A global climatology of stratospheric aerosol surface area density deduced from Stratospheric Aerosol and Gas Experiments II measurements: 1984-1994, J. Geophys. Res., 102, 8967-8976, 1997.
Timmreck, C. and Graf, H.-F.: The initial dispersal and radiative forcing of a Northern Hemisphere mid-latitude super volcano: A model study, Atmos. Chem. Phys., 6, 35-49, 2006, http://www.atmos-chem-phys.net/6/35/2006/.

Timmreck, C., Graf, H.-F., and Kirchner, I.: A one and half year interactive MA/ECHAM4 simulation of Mount Pinatubo Aerosol, J. Geophys. Res., 104, 9337-9360, doi:10.1029/1999JD900088, 1999.

Timmreck, C., Graf, H.-F., and Steil, B.: Aerosol chemistry interactions after the Mt. Pinatubo eruption, in Volcanism and the Earth's Atmosphere, 214-225, AGU Monograph 139, 2003.

Trepte, C. R. and Hitchman, M. H.: Tropical stratospheric circulation deduced from satellite aerosol data, Nature, 355, 626-628, 1992.

Tupper, A., Carn, S., Davey, J., Kamada, Y., Potts, R., Prata, F., and Tokuno, M.: An evaluation of volcanic cloud detection techniques during recent significant eruptions in the western Ring of Fire,, Remote Sensing of Environment, 91, 27-46, doi:10.1016/j.rse.2004.02.004, 2004.

Vignati, E., Wilson, J., and Stier, P.: M7: An efficient size resolved aerosol microphysics module for large-scale aerosol transport models, J. Geophys. Res., 109, D22202, doi:10.1029/ 2003JD004485, 2004.

Wen, S. and Rose, W. I.: Retrieval of sizes and total mases of particles in volcanic clouds using AVHRR bands 4 and 5, J. Geophys. Res., 99, 5421-5431, 1994.

Wiesner, M., Wetzel, A., Catane, S. G., Listanco, E., and Mirabueno, H. T.: Grain size, areal thickness distribution and controls on sedimentation of the $1991 \mathrm{Mt}$. Pinatubo tephra layer in the South China Sea, Bull. Volcanol., 66, 226-242, 2004. 